\title{
CAPACIDAD PROBIÓTICA DE BACTERIAS LÁCTICAS AISLADAS DE CHICHA DE MOLLE
}

\author{
Jhanina Rodríguez Carrasco, Paula García-Godos Alcázar ${ }^{{ }^{*}}$
}

\begin{abstract}
RESUMEN
La investigación tuvo como objetivos aislar e identificar bacterias lácticas (BAL), evaluar la capacidad probiótica in vitro e in vivo de bacterias lácticas aisladas de chicha de molle, para ello se muestreó chichas de molle elaboradas artesanalmente de las provincias de Huanta y Huamanga, aislando 55 cepas BAL e identificando a Lactobacillus plantarum, Lactobacillus maltaromicus y Leuconostoc mesenteroides en base a la coloración Gram, producción de gas, gluconato y fermentación de azúcares. Para evaluar la capacidad probiótica in vitro se realizaron pruebas de antagonismo entre BAL con cuatro microorganismos patógenos (Escherichia coli ATCC 25922, Salmonella typhimurium ATCC 14028, Staphylococus aureus ATCC 25923 y Candida albicans ATCC 90028), mostrándose que 14 de las 55 cepas BAL producen sustancias inhibitorias de amplio espectro; asimismo, se evaluó la capacidad de tolerancia a condiciones gastrointestinales de cepas BAL, realizando ensayos a diferentes $\mathrm{pH}_{\mathrm{s}}$, diferentes concentraciones de sales biliares y extracto gástrico artificial, resultando 25 cepas BAL con capacidad de tolerancia gastrointestinal y se seleccionaron cuatro cepas con mayor diámetro de halos de inhibición y cepas tolerantes a condiciones gastrointestinales siendo las cepas: BL-1 (Lactobacillus plantarum), BL-26 (Lactobacillus maltaromicus), BL-27 (Lactobacillus plantarum) y BL-53 (Lactobacillus maltaromicus), a las cuales se evaluaron la capacidad probiótica in vivo en 20 ratas para luego realizar recuento de BAL en el intestino a los 21 días, encontrándose en el grupo de estudio con BAL a $60 \times 10^{19} \mathrm{UFC} /$ $\mathrm{mL}$, mientras en el tratamiento con BAL más yacón a $25 \times 10^{24} \mathrm{UFC} / \mathrm{mL}$ y los tratamientos de yacón y control a $50 \times 10^{14} \mathrm{UFC} / \mathrm{mL}$ de BAL obteniéndose una de ganancia de peso en ratas en el grupo de estudio de BAL más yacón de $46 \mathrm{~g}$, mientras con bacterias lácticas se tuvo $24 \mathrm{~g}$ y $16 \mathrm{~g}$ en el grupo control y extracto de yacón. En consecuencia esta investigación demuestra que la toma diaria de bebidas fermentadas tradicionales favorece el incremento de Lactobacillus en la microbiota intestinal.
\end{abstract}

Palabras clave: Bacterias lácticas, capacidad probiótica, yacón, chicha de molle.

\footnotetext{
$\mathrm{a}^{*}$ Facultad de Ciencias Biológicas, Universidad Nacional San Cristóbal de Humanga, Portal Independencia № 57. Ayacucho-Perú.paulagga30@hotmail.com
} 


\title{
PROBIOTIC CAPACITY OF LACTIC ACID BACTERIA ISOLATED FROM CHICHA OF MOLLE
}

\begin{abstract}
The objective of the research was to isolate and identify lactic acid bacteria (BAL), to evaluate the in vitro and in vivo probiotic capacity of lactic bacteria isolated from chicha of molle. For this purpose, samples of chicha of molle were prepared from the provinces of Huanta and Huamanga, isolating 55 BAL strains and identifying Lactobacillus plantarum, Lactobacillus maltaromicus and Leuconostoc mesenteroides based on Gram stain, gas production, gluconate and fermentation of sugars. In order to evaluate the in vitro probiotic capacity, BAL antagonism with four pathogenic microorganisms (Escherichia coli ATCC 25922, Salmonella typhimurium ATCC 14028, Staphylococus aureus ATCC 25923 y Candida albicans ATCC 90028) was performed, showing that 14 of the 55 BAL strains produce broad spectrum inhibitory substances. Evaluated the capacity of tolerance to gastrointestinal conditions of BAL strains, performing tests at different $\mathrm{pHs}$, different concentrations of bile salts and artificial gastric juice, resulting $25 \mathrm{BAL}$ strains with capacity of gastrointestinal tolerance and 4 strains were selected with greater diameter of inhibition halos and (Lactobacillus plantarum), BL-26 (Lactobacillus maltaromicus), BL-27 (Lactobacillus plantarum) and BL53 (Lactobacillus maltaromicus), which were evaluated for probiotic capacity in live in 20 rats and then perform a BAL count in the intestine at 21 days, being in the study group with BAL at $60 \times 10^{19} \mathrm{UFC} / \mathrm{mL}$, while in the treatment with BAL plus yacon at $25 \times 10^{24} \mathrm{UFC} / \mathrm{mL}$ and treatments of yacon and control at $50 \times 10^{14} \mathrm{UFC} / \mathrm{mL}$ of BAL obtaining a weight gain in Rats in the study group of BAL plus yacon of $46 \mathrm{~g}$, while with lactic bacteria was $24 \mathrm{~g}$ and $16 \mathrm{~g}$ in the control group and extract of yacon. Consequently, this research demonstrates that the daily intake of traditional fermented beverages favors the increase of Lactobacillus in the intestinal microbiota.
\end{abstract}

Key words: Lactic bacteria, probiotic capacity, yacon, chicha of molle.

\section{INTRODUCCIÓN}

Por la reciente preocupación mundial sobre asuntos de salud y la alimentación, los alimentos funcionales tienen un papel importante en la industria alimentaria, por tanto, se necesita explorar procesos nuevos y poner énfasis en este tipo de industrias. Los alimentos fermentados como la chicha de molle contienen microorganismos como las bacterias lácticas, las cuales son consideradas como probióticos. Una bebida probiótica es definida como un suplemento microbiano, que tiene efectos benéficos mejorando el balance microbiano intestinal. El intestino cuenta con un sinnúmero de microorganismos presentes en la porción final del tracto gastrointestinal humano ${ }^{1}$.

En el intestino delgado la microbiota varía según el segmento intestinal, por sí misma no produce alteraciones, constituyendo un verdadero cultivo autorregulable. Asimismo, la 
variación de estos microorganismos benéficos de nuestra microbiota intestinal pueden ocasionar infecciones persistentes en el tracto intestinal, que contribuye a la pérdida de una de las características funcionales más importantes para el control de la proliferación de la microbiota intestinal; así en la chicha de molle se encuentran microorganismos beneficiosos para el hombre, como las bacterias lácticas que modifican favorablemente el balance de la microbiota intestinal, favorecen una buena digestión, inhiben el crecimiento de ciertas bacterias patógenas, potencian la función inmunológica y aumentan la resistencia a las infecciones ${ }^{2}$.

Las personas con colonias intestinales de estas bacterias benéficas están mejor equipadas para combatir el crecimiento de las bacterias que causan enfermedades. Los lactobacilos y los bacilos bífidos mantienen un balance sano de la microbiota intestinal al producir compuestos orgánicos, como el ácido láctico, agua oxigenada y ácido acético, que aumentan la acidez intestinal e inhiben el desarrollo de muchos microorganismos nocivos debido a la producción de sustancias llamadas bacteriocinas, que funcionan como antibióticos naturales, matando a los microorganismos no deseados ${ }^{3}$.

Es fundamental la relación existente entre la microbiota intestinal y el estado de salud de las personas. Una mala alimentación produce una elevada presencia de sustancias perjudiciales, que al ser utilizadas por bacterias nocivas presentes en el intestino afectan la salud del receptor ${ }^{4}$.

En el intestino, tanto los microorganismos beneficiosos como aquellos potencialmente patógenos pueden competir por los mismos nutrientes para crecer y reproducirse. Por lo tanto, cuanto mayor es la población de las bacterias beneficiosas en el intestino, mayor será la competencia con los microorganismos patógenos ${ }^{4}$. El estudio tuvo como objetivos: aislar e identificar las bacterias lácticas aisladas de la chicha de molle, evaluar la capacidad probiótica in vitro de las bacterias lácticas aisladas de la chicha de molle y evaluar la capacidad probiótica in vivo de bacterias lácticas aisladas de la chicha de molle en Ratus norvegicus "rata" cepa Holtzman.

\section{PARTE EXPERIMENTAL}

Las muestras estuvieron conformadas por 55 chichas de molle procedente de la provincia de Huanta del distrito de Luricocha comunidad rural Secclla y de la provincia de Huamanga distrito de Ayacucho, Pacaycasa, anexo Ocopa; Tambillo, anexo Condaray, y distrito de Jesús Nazareno. Se desarrollaron las siguientes técnicas:

Aislamiento directo de bacterias lácticas.- Se aislaron bacterias provenientes de chicha de molle elaboradas de manera artesanal, para lo cual se tomó una asada de la muestra fermentada en Agar Lactobacilli, se sembró por estrías, posteriormente se incubó a $37^{\circ} \mathrm{C}$ por 24 horas y finalmente las colonias se repicaron para el cepario ${ }^{5}$. 
Identificación de bacterias lácticas.- Se evaluó las características microscópicas mediante la coloración de Gram, esta prueba se hizo a partir de un cultivo joven (18-24h) en Agar Lactobacilli $^{5}$. Y para las pruebas bioquímicas se llevó a cabo la evaluación de la capacidad fermentativa con diferentes carbohidratos como: arabinosa, celobiosa, fructosa, galactosa, glucosa, lactosa, maltosa, manitol, manosa, rafibinosa, sallicilina, sorbitol sacarosa, xilosa, almidón e inulina ${ }^{5}$.

\section{Capacidad probiótica in vitro}

Crecimiento en disco de microorganismos.- Se reactivó las cepas patógenas en Caldo Nutritivo (Escherichia coli, ATCC 25922, Staphylococcus aureus ATCC 25923, Salmonella typhimurium ATCC 14028) y en Caldo Sabouroud (Candida albicans ATCC 90028) a $37^{\circ} \mathrm{C}$ por 14 horas. Asimismo, se reactivó las bacterias lácticas en Caldo Lactobacilli a $37^{\circ} \mathrm{C} / 14$ h y se comparó con el tubo $\mathrm{N}^{\mathrm{o}} 2$ de la escala de Mac Farland con $109 \mathrm{UFC} / \mathrm{mL}$. Asimismo, se dispuso en placas petri con Agar Lactobacilli, en la que se realizaron con la ayuda de un sacabocado discos de $6 \mathrm{~mm}$ de diámetro a partir de la placa con Medio Lactobacilli y se colocó en placas con Agar Müeller Hintong y Agar Nutritivo, luego con las cepas de bacterias lácticas reactivadas se colocó exactamente en el centro de cada disco $20 \mu \mathrm{L}$ de BAL reactivadas ${ }^{6}$.

Prueba de antagonismo.- Se sumergió un hisopo estéril en suspensión de células a partir de las cepas de Escherichia coli, Salmonella typhimurium, Staphylococus aureus y Candida albicans comparando con el tubo $\mathrm{N}^{\mathrm{o}} 2$ de la Escala de Mac Farland, presionando firmemente sobre la pared interior del tubo por encima del nivel del líquido para remover el exceso del inóculo. Se inoculó en la superficie de la placa con Agar Müeller Hintong y Agar Nutritivo, estirando con el hisopo estéril en tres direcciones, para asegurar una distribución uniforme del inóculo, antes de colocar los discos se dejó secar la placa a temperatura ambiente durante 3 a 5 minutos para eliminar el exceso de humedad superficial.

Así, se colocaron los discos sobre la superficie del Agar Müeller Hintong presionando suavemente sobre el disco para asegurar el contacto completo con la superficie del Agar. Se incubaron las placas en posición invertida a $37^{\circ} \mathrm{C}$ por 24 horas para bacterias y $25^{\circ} \mathrm{C}$ por 48 horas para levadura para finalmente medir los halos de inhibición ${ }^{6}$.

\section{Tolerancia a condiciones gastrointestinales}

Tolerancia a pH ácido.- Se preparó tubos con Caldo Lactobacilli y se ajustó a pH 1.0, 1,5 y 2,0 con $\mathrm{HCl} 0,1 \mathrm{~N}$ luego se vertió el inóculo de las cepas BAL en tubos y se dejó en incubación a $37^{\circ} \mathrm{C}$ por 24 horas, finalmente se observó el crecimiento por turbidez ${ }^{7}$.

Tolerancia a extractos gástricos.- Se reactivó las cepas BAL, luego se preparó extracto gástrico artificial, para lo cual se tomó $0,2 \mathrm{~g}$ de $\mathrm{NaCl}$ y $0,32 \mathrm{~g}$ de pepsina ajustando a $\mathrm{pH}$ final de 2,0 - 2,3 con $\mathrm{HCl}$ concentrado, se completó a $100 \mathrm{~mL}$ con agua destilada estéril. Como control se ajustó extracto gástrico artificial a un $\mathrm{pH}$ de 6,5 -7,0 con $\mathrm{NaOH} 5 \mathrm{~N}$, luego se llevó 
a esterilización, así mismo se vertió $1 \mathrm{~mL}$ de inóculo en $9 \mathrm{~mL}$ del extracto gástrico artificial pH 2,0 - 2,3 y pH 6,5-7,0 (control) y se incubó a $37^{\circ} \mathrm{C}$, luego de 24 horas se observó la viabilidad celular por turbidez ${ }^{7}$.

Tolerancia a sales biliares.- Se preparó bilis de buey al $0,05,0,1,0,15,0,3 \% \mathrm{p} / \mathrm{v}$ en tubos con Caldo Lactobacilli y se vertió $100 \mu \mathrm{L}$ cepas BAL, se dejó en incubación a $37{ }^{\circ} \mathrm{C}$ por 24 horas se observó el crecimiento por turbidez?

Evaluación de la densidad poblacional in vivo de bacterias lácticas y cepas patógenas. Se utilizaron 20 ratas hembras adultas Ratus norvegicus cepa Holtzman de siete semanas de edad, procedentes del Instituto Nacional de Salud - Lima, cuyo peso corporal oscilaba entre 180-200 g al término de la cuarentena (7 días), durante la cual los animales se adaptaron a las condiciones del laboratorio. La temperatura se mantuvo en $20 \pm 2{ }^{\circ} \mathrm{C}$, la humedad entre $60 \pm 10 \%$ y los ciclos de luz - oscuridad fueron de 12 horas. El alimento administrado a los animales durante el estudio fue pienso preparado en el laboratorio de biotecnología, constituido por $50 \%$ de cereales (maíz, avena y arroz), $25 \%$ de leguminosas (frijol y lentejas) y $25 \%$ de frutos secos (almendras y pasas). El acceso al agua y al alimento fue ad libitum y para cada tratamiento se utilizaron cuatro ratas. Toda la manipulación de los animales se realizó de acuerdo con los principios éticos para el uso de los animales de laboratorio del Perú.

Estandarización de la carga microbiana de bacterias lácticas.- Para la estandarización de carga microbiana de BAL se reactivó las cepas patógenas y una cepa BAL escogida al azar, luego se verificó la turbidez con la escala de Mac Farland (tubo 2) con 109UFC/mL, para posteriormente realizar el recuento en placa.

Evaluación in vivo de la densidad poblacional de bacterias lácticas.- A cada uno de los animales de experimentación se le inoculó el probiótico diariamente. Para el tratamiento 1, se inoculó en proporción 1:1 de bacterias lácticas y extracto de yacón, respectivamente, para el tratamiento $2,2 \mathrm{~mL}$ de bacterias lácticas, para el tratamiento $3,2 \mathrm{~mL}$ de yacón y el tratamiento 4 (control) no se inoculó ni bacterias lácticas ni yacón.

El diseño experimental constituido por:

Tabla 1. Diseño experimental

\begin{tabular}{|c|c|}
\hline $\mathbf{N}^{\mathbf{0}}$ & Tratamiento \\
\hline 1 & 4 ratas (yacón + BAL) \\
\hline 2 & 4 ratas (BAL) \\
\hline 3 & 4 ratas (yacón) \\
\hline 4 & 4 ratas (control) \\
\hline
\end{tabular}


Sacrificio de animales.- Todos los animales fueron sacrificados a los 21 días, por lo cual previamente fueron anestesiados con atmósfera de éter y luego sacrificados por dislocación cervical y, finalmente, se extrajo el intestino delgado al cual se realizó lavados con agua peptonada al $1 \%$. Luego se realizó diluciones hasta $10^{-20}$ y se sembró por incorporación las dos últimas diluciones por duplicado en Agar Lactobacilli e incubó a $37^{\circ} \mathrm{C}$ por 24 horas y se realizó finalmente el recuento en placa.

Análisis estadístico.- Se realizó la prueba de ANOVA con un nivel de significancia de $5 \%$ la cual contribuyó para la identificación de diferencia de densidades poblacionales de BAL para ello se empleó el software estadístico SPSS 23.

\section{RESULTADOS Y DISCUSIÓN}

En la figura 1 se observa la formación de halos de inhibición producidas por bacterias lácticas (BAL) frente a cepas patógenas como Escherichia coli, y Salmonella typhimurium (Gram negativas) y Staphylococcus aureus (Gram positivas) y a Candida albicans (levadura), reportando que las 55 cepas de BAL aisladas producen sustancias inhibitorias frente a microorganismos patógenos, siendo el diámetro mínimo resistente $14 \mathrm{~mm}, 15 \mathrm{~mm}, 15$ $\mathrm{mm}$ y $14 \mathrm{~mm}$, respectivamente, observándose que 14 cepas producen halos de inhibición frente a las cuatro cepas patógenas, deduciendo que estas cepas producen bacteriocinas de amplio espectro, visualizando que las cepas de Lactobacillus plantarum y Lactobacillus maltaromicus presentan mayor capacidad de inhibición en comparación con las cepas de Leuconostoc mesenteroides, resultado similar en el estudio de la capacidad antagónica de bacterias lácticas aisladas de chicha de molle frente a Escherichia coli, Staphylococus aureus y Candida albicans, siendo las especies de Lactobacillus plantarum con mayor capacidad antagónica en comparación a Leuconostoc mesenteroides ${ }^{5}$. Para determinar la capacidad probiótica de una cepa, esta debe cumplir con la producción de sustancias antimicrobianas como el ácido láctico, peróxido de hidrógeno y bacteriocinas; estos compuestos reducen el número de células patógenas, afectando el metabolismo bacteriano o la producción de toxinas, en este sentido se llevó a cabo el estudio con la finalidad de evidenciar la posible capacidad inhibidora de las cepas aisladas de la chicha de molle y para realizar la selección de cepas, se basó en que las cepas fueran activas frente a cuatro microorganismos patógenos los cuales deben evidenciarse mediante la producción de sustancias inhibitorias. Entre las especies de Lactobacillus que desempeñan un papel fundamental en el tracto digestivo podemos citar a Lactobacillus plantarum las cuales se menciona en la investigación de la actividad inhibitoria de los mismos, frente a cepas de Enterobacteriaceae y Staphylococcus aureus demuestra que Lactobacillus plantarum producen un sistema inhibitorio y acción antagonista contra los microorganismos patógenos antes mencionados 9 , estos resultados coinciden con la producción de bacteriocinas producidas por las cepas BAL aisladas de chicha de molle. 


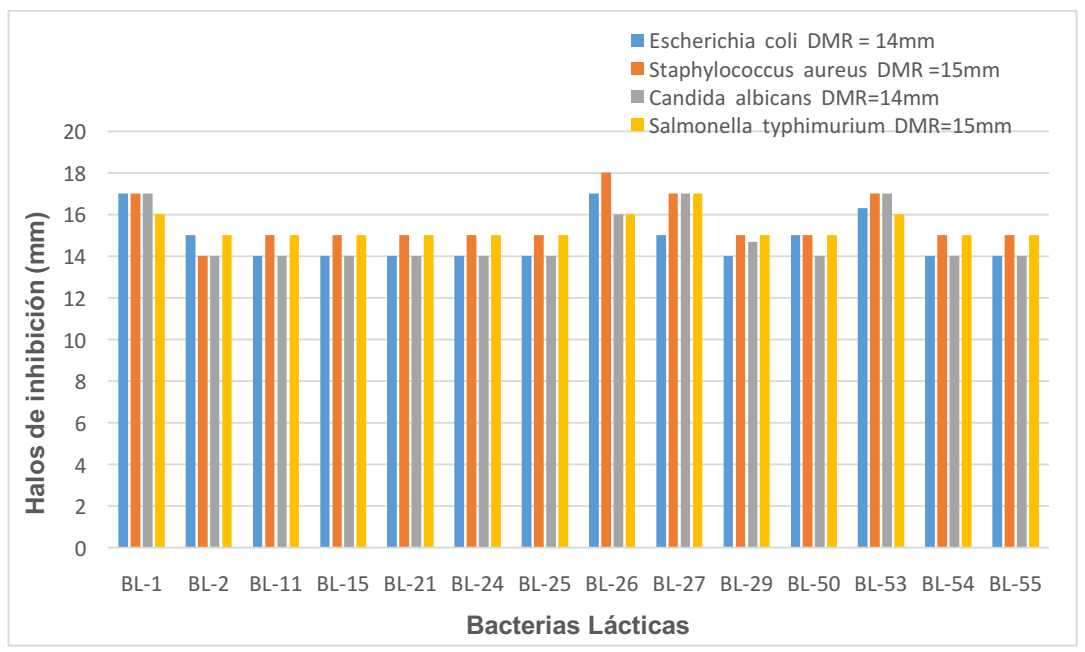

Codificación: BL-1,2,11,15,21,24,25,26,27,29,54,55 = Lactobacillus plantarum. BL-26,50.5 $5^{3}$ Lactobacillus maltaromicus.

Figura 1. Formación de halos de inhibición producidas por bacterias lácticas frente a cepas patógenas.

Un requisito importante para determinar la utilización de los Lactobacillus como probiótico, es que las cepas sean capaces de adherirse a las células intestinales ya que constituye un prerequisito para la colonización, dichos Lactobacillus deben soportar las barreras potenciales tales como $\mathrm{pH}$ del estómago, presencia de bilis y las interacciones con otros microorganismos presentes en el tracto gastrointestinal, por tanto, se requieren cepas ácido-tolerantes así como tolerantes a extractos gástricos y fluidos duodenales 5 .

Así, para evaluar la capacidad probiótica in vitro se realizaron pruebas de tolerancia gastrointestinal, en las cuales se evaluó el crecimiento de BAL a diferentes concentraciones de $\mathrm{pH}$, concentraciones de bilis y extracto gástrico artificial, experimentadas a las 55 cepas. En la tabla 2 se observa la capacidad de tolerar estas condiciones, para ello las bacterias lácticas requieren complejos de proteínas y carbohidratos para adherirse a las células intestinales. Para algunas cepas, un material tipo polisacárido que facilita la unión, mientras que otras cepas involucran complejos de lípidos y proteínas en este mecanismo ${ }^{10,11}$.

A partir de los estudios realizados de las cepas de Lactobacillus provocan un adecuado efecto probiótico en el intestino humano, dado que son capaces de resistir a estas condiciones. Estos resultados coinciden con los obtenidos en el estudio, resultando de ello que 25 cepas aisladas de chicha de molle tienen capacidad de tolerar condiciones gastrointestinal in vitro ${ }^{12}$. 
Tabla 2. Tolerancia gastrointestinal in vitro de bacterias lácticas asiladas de chicha de molle.

\begin{tabular}{|l|c|c|c|c|c|c|c|c|c|}
\hline & & & & & & & & & \\
\hline CEPAS & & $\mathbf{p H}$ & & & $\begin{array}{l}\text { Bilis } \\
\mathbf{( \% )}\end{array}$ & & & $\begin{array}{l}\text { Extracto } \\
\text { Gástrico }\end{array}$ & Tolerancia \\
\hline & 1.0 & 1.5 & 2.0 & 0.05 & 0.10 & 0.15 & 0.30 & & \\
\hline & & & & & & & & & \\
\hline BL-1 & $\sqrt{ }$ & $\sqrt{ }$ & $\sqrt{ }$ & $\sqrt{ }$ & $\sqrt{ }$ & $\sqrt{ }$ & $\sqrt{ }$ & $\sqrt{ }$ & SI \\
\hline BL-2 & $\sqrt{ }$ & $\sqrt{ }$ & $\sqrt{ }$ & $\sqrt{ }$ & $\sqrt{ }$ & $\sqrt{ }$ & $\sqrt{ }$ & $\sqrt{ }$ & SI \\
\hline BL-3 & $\sqrt{ }$ & $\sqrt{ }$ & $\sqrt{ }$ & $\sqrt{ }$ & $\sqrt{ }$ & $\sqrt{ }$ & $\sqrt{ }$ & $\sqrt{ }$ & SI \\
\hline BL-6 & $\sqrt{ }$ & $\sqrt{ }$ & $\sqrt{ }$ & $\sqrt{ }$ & $\sqrt{ }$ & $\sqrt{ }$ & $\sqrt{ }$ & $\sqrt{ }$ & SI \\
\hline BL-7 & $\sqrt{ }$ & $\sqrt{ }$ & $\sqrt{ }$ & $\sqrt{ }$ & $\sqrt{ }$ & $\sqrt{ }$ & $\sqrt{ }$ & $\sqrt{ }$ & SI \\
\hline BL-8 & $\sqrt{ }$ & $\sqrt{ }$ & $\sqrt{ }$ & $\sqrt{ }$ & $\sqrt{ }$ & $\sqrt{ }$ & $\sqrt{ }$ & $\sqrt{ }$ & SI \\
\hline BL-11 & $\sqrt{ }$ & $\sqrt{ }$ & $\sqrt{ }$ & $\sqrt{ }$ & $\sqrt{ }$ & $\sqrt{ }$ & $\sqrt{ }$ & $\sqrt{ }$ & SI \\
\hline BL-12 & $\sqrt{ }$ & $\sqrt{ }$ & $\sqrt{ }$ & $\sqrt{ }$ & $\sqrt{ }$ & $\sqrt{ }$ & $\sqrt{ }$ & $\sqrt{ }$ & SI \\
\hline BL-15 & $\sqrt{ }$ & $\sqrt{ }$ & $\sqrt{ }$ & $\sqrt{ }$ & $\sqrt{ }$ & $\sqrt{ }$ & $\sqrt{ }$ & $\sqrt{ }$ & SI \\
\hline BL-21 & $\sqrt{ }$ & $\sqrt{ }$ & $\sqrt{ }$ & $\sqrt{ }$ & $\sqrt{ }$ & $\sqrt{ }$ & $\sqrt{ }$ & $\sqrt{ }$ & SI \\
\hline BL-23 & $\sqrt{ }$ & $\sqrt{ }$ & $\sqrt{ }$ & $\sqrt{ }$ & $\sqrt{ }$ & $\sqrt{ }$ & $\sqrt{ }$ & $\sqrt{ }$ & SI \\
\hline BL-24 & $\sqrt{ }$ & $\sqrt{ }$ & $\sqrt{ }$ & $\sqrt{ }$ & $\sqrt{ }$ & $\sqrt{ }$ & $\sqrt{ }$ & $\sqrt{ }$ & SI \\
\hline BL-25 & $\sqrt{ }$ & $\sqrt{ }$ & $\sqrt{ }$ & $\sqrt{ }$ & $\sqrt{ }$ & $\sqrt{ }$ & $\sqrt{ }$ & $\sqrt{ }$ & SI \\
\hline BL-26 & $\sqrt{ }$ & $\sqrt{ }$ & $\sqrt{ }$ & $\sqrt{ }$ & $\sqrt{ }$ & $\sqrt{ }$ & $\sqrt{ }$ & $\sqrt{ }$ & SI \\
\hline BL-44 & $\sqrt{ }$ & $\sqrt{ }$ & $\sqrt{ }$ & $\sqrt{ }$ & $\sqrt{ }$ & $\sqrt{ }$ & $\sqrt{ }$ & $\sqrt{ }$ & SI \\
\hline BL-23 & $\sqrt{ }$ & $\sqrt{ }$ & $\sqrt{ }$ & $\sqrt{ }$ & $\sqrt{ }$ & $\sqrt{ }$ & $\sqrt{ }$ & $\sqrt{ }$ & SI \\
\hline BL-24 & $\sqrt{ }$ & $\sqrt{ }$ & $\sqrt{ }$ & $\sqrt{ }$ & $\sqrt{ }$ & $\sqrt{ }$ & $\sqrt{ }$ & $\sqrt{ }$ & SI \\
\hline BL-25 & $\sqrt{ }$ & $\sqrt{ }$ & $\sqrt{ }$ & $\sqrt{ }$ & $\sqrt{ }$ & $\sqrt{ }$ & $\sqrt{ }$ & $\sqrt{ }$ & SI \\
\hline BL-26 & $\sqrt{ }$ & $\sqrt{ }$ & $\sqrt{ }$ & $\sqrt{ }$ & $\sqrt{ }$ & $\sqrt{ }$ & $\sqrt{ }$ & $\sqrt{ }$ & SI \\
\hline BL-44 & $\sqrt{ }$ & $\sqrt{ }$ & $\sqrt{ }$ & $\sqrt{ }$ & $\sqrt{ }$ & $\sqrt{ }$ & $\sqrt{ }$ & $\sqrt{ }$ & SI \\
\hline BL-48 & $\sqrt{ }$ & $\sqrt{ }$ & $\sqrt{ }$ & $\sqrt{ }$ & $\sqrt{ }$ & $\sqrt{ }$ & $\sqrt{ }$ & $\sqrt{ }$ & SI \\
\hline BL-50 & $\sqrt{ }$ & $\sqrt{ }$ & $\sqrt{ }$ & $\sqrt{ }$ & $\sqrt{ }$ & $\sqrt{ }$ & $\sqrt{ }$ & $\sqrt{ }$ & SI \\
\hline BL-53 & $\sqrt{ }$ & $\sqrt{ }$ & $\sqrt{ }$ & $\sqrt{ }$ & $\sqrt{ }$ & $\sqrt{ }$ & $\sqrt{ }$ & $\sqrt{ }$ & SI \\
\hline BL-54 & $\sqrt{ }$ & $\sqrt{ }$ & $\sqrt{ }$ & $\sqrt{ }$ & $\sqrt{ }$ & $\sqrt{ }$ & $\sqrt{ }$ & $\sqrt{ }$ & SI \\
\hline BL-55 & $\sqrt{ }$ & $\sqrt{ }$ & $\sqrt{ }$ & $\sqrt{ }$ & $\sqrt{ }$ & $\sqrt{ }$ & $\sqrt{ }$ & $\sqrt{ }$ & SI \\
\hline & & & & & & & & & \\
\hline
\end{tabular}

$\mathrm{BL}=$ Bacterias Lácticas

En la tabla 3 se reporta la carga microbiana de bacterias lácticas halladas en los intestinos de los animales de experimentación que son muy variables, en el cual se evidencia que las bacterias lácticas son capaces de adherirse al intestino, existiendo mayor número de carga microbiana en los tratamientos de las cuatro cepas más la utilización del yacón, esto debido a la presencia del prebiótico el cual cumple el papel de nutriente para los probióticos, en base a las cuatro cepas experimentales no existe diferencia en la carga microbiana obteniéndose una carga microbiana de $25 \times 10^{24} \mathrm{UFC} / \mathrm{mL}$ en el grupo de estudio con BAL más yacón, mientras que en el tratamiento con BAL $60 \times 10^{19} \mathrm{UFC} / \mathrm{mL}$, de ello podemos mencionar que las cuatro cepas probióticas tienen la misma capacidad de adherencia al intestino, en cambio en el grupo de estudio, en los cuales se experimentó independientemente con el yacón y el grupo control reportan una carga de $50 \times 10^{14} \mathrm{UFC} / \mathrm{mL}$, en base a ello se observa un incremento de $10 \times 10^{5} \mathrm{UFC} / \mathrm{mL}$ de BAL con respecto a la utilización de BAL y $25 \times 10^{10} \mathrm{UFC} / \mathrm{mL}$ con BAL más yacón. Siendo el yacón, condicionante para una mayor densidad poblacional de las cepas lácticas, debido a la presencia de fructooligosacáridos como fuente de carbono estimulando selectivamente al crecimiento de microorganismos probióticos ${ }^{8}$, en el estudio de la capacidad prebiótica de Smallantus sonchifolia en Rattus norvergicus, menciona que los prebióticos como el yacón contienen fructooligosacáridos que estimulan el crecimiento de número de 
UFC de Lactobacillus. En consecuencia, podemos indicar que administrar una mezcla de una cepa BAL con el extracto de yacón administrado en proporción 1:1 determinar un grado de adhesión notable y que facilita el desplazamiento de bacterias lácticas en el tracto digestivo de los individuos en experimentación.

Tabla 3. Densidad poblacional de bacterias lácticas aisladas de chicha de molle evaluadas en el intestino de Rattus norvergicus "rata" a los 21 días administrado.

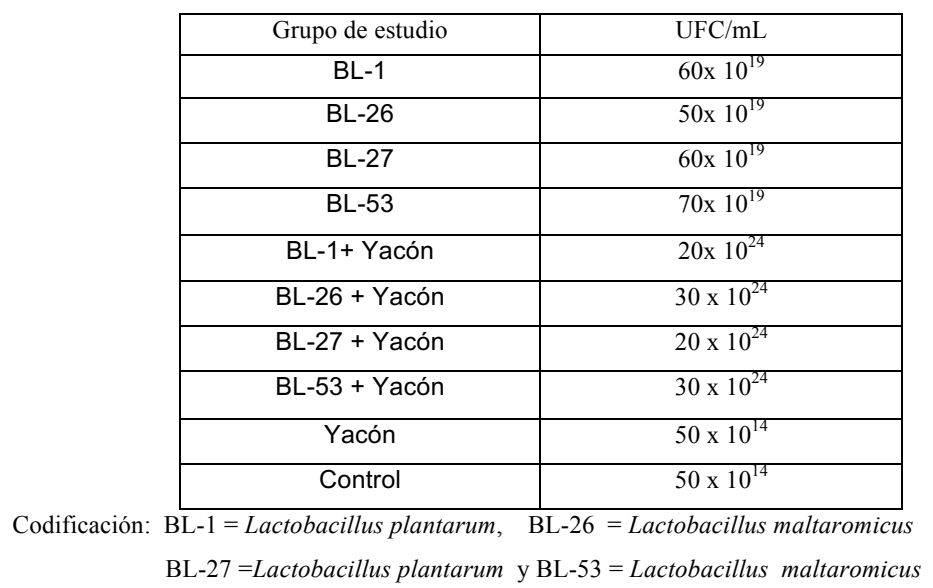

En base a ello se seleccionó cuatro cepas BAL con mayor diámetro de inhibición frente a microorganismos patógenos y tolerantes a condiciones gastrointestinales, siendo las seleccionadas BL-1 de la especie Lactobacillus plantarum, BL-26 de la especie Lactobacillus maltaromicus, BL-27 Lactobacillus plantarum y BL-53 de la especie Lactobacillus maltaromicus a las cuales se evaluaron la capacidad probiótica in vivo.

Para la evaluación in vivo de la capacidad probiótica de cepas se administró bacterias lácticas a 20 animales de experimentación (Rattus norvergicus) del cual podemos destacar que no se observaron efectos negativos ni en el comportamiento ni en el bienestar de las 20 ratas hembras a lo largo de todo el estudio realizado. En la figura 2, observamos los resultados de la aplicación de los tratamientos en cuanto a la ganancia de peso de ratas, encontrándose que las ratas que recibieron bacterias lácticas más extracto de yacón obtuvieron 46 gr de ganancia de peso mientras que en la ingesta de BAL se obtuvo 24 gr y 16 gr de ganancia de peso en el grupo control y extracto de yacón, de ello deducimos que las ratas que recibieron bacterias lácticas más extracto de yacón lograron mayores ganancias en peso a comparación con los que no recibieron el tratamiento, debido a la mayor asimilación de nutrientes y ausencia de enfermedades e infecciones gástricas durante el tiempo de estudio. El mayor incremento de peso puede ser atribuido a un mejor estado físico en las ratas, como lo reportan en el estudio sobre el efecto de bacterias probióticas en animales de experimentación en el cual estableció, que la ganancia diaria de peso en animales influyen factores como la ingesta de bacterias probióticas, estimulando su resistencia a microorganismos patógenos así como activando su respuesta inmune ${ }^{13}$. 


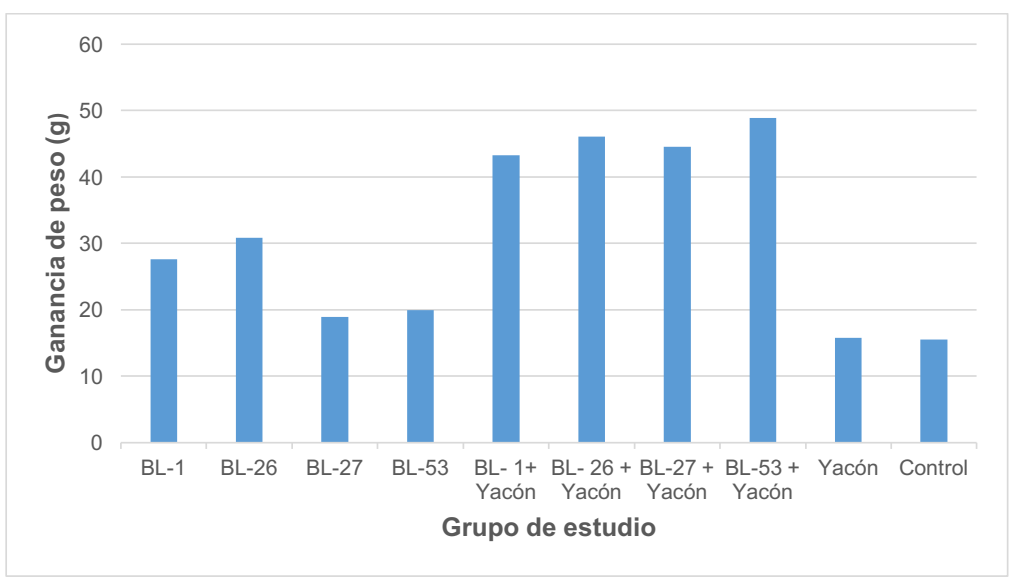

Figura 2. Ganancia de peso de Rattus novergicus "rata" sometidas a cuatro cepas de bacterias lácticas aisladas de chicha de molle.

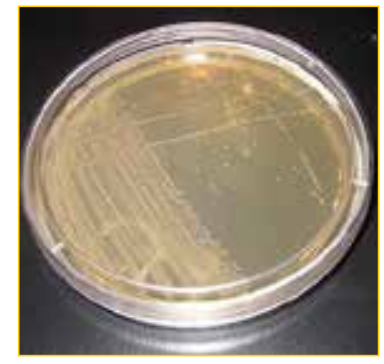

Bacteria Láctica BL-26

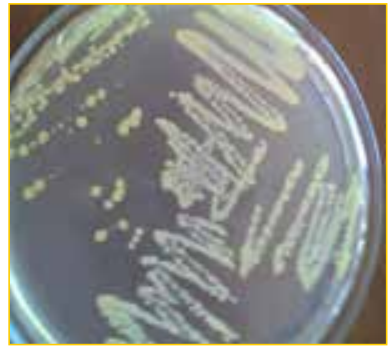

Bacteria Láctica BL-1

Figura 3. Características Macroscópicas en Agar Extracto de Tomate

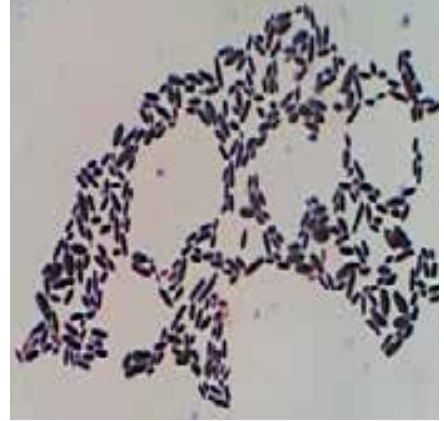

Bacteria Láctica BL-26

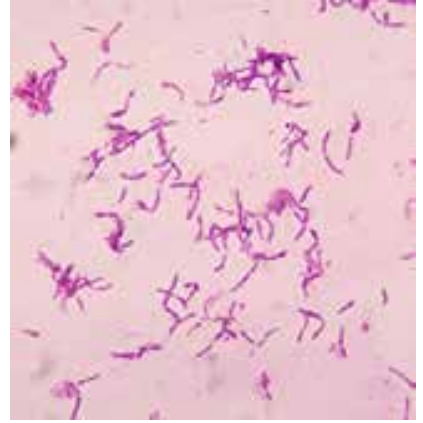

Bacteria Láctica BL-1

Figura 4. Características Microscópicas (100X) 


\section{CONCLUSIONES}

1. Se aisló e identificó 55 cepas nativas de bacterias lácticas de chicha de molle, siendo identificadas las especies: Lactobacillus plantarum, Leuconostoc mesenteroides y Lactobacillus maltaromicus.

2. En la capacidad probiótica in vitro, se obtuvo que 14 cepas BAL aisladas producen sustancias inhibitorias de amplio espectro frente a microorganismos patógenos y 25 cepas BAL resistentes a condiciones gastrointestinales.

3. En la capacidad probiótica in vivo, se consiguió que en el tratamiento con bacterias lácticas más extracto de yacón se obtuvo $25 \times 10^{24} \mathrm{UFC} / \mathrm{mL}$ de BAL, comportándose el yacón como un prebiótico.

4. Se obtuvo $46 \mathrm{~g}$ de ganancia de peso en las ratas en el tratamiento de BAL más extracto de yacón.

\section{AGRADECIMIENTO}

Las autoras agradecen el apoyo en el financiamiento para la ejecución de la investigación a la Universidad Nacional de San Cristóbal de Huamanga.

\section{BIBLIOGRAFÍA}

1. Icaza-Chávez M. E. Microbiota intestinal en la salud y la enfermedad. Rev Gastroenterol Mex. 2013; 78(4): 240-248.

2. Sebastián JJ. Revisión del papel de los probióticos en patología gastrointestinal del adulto. Gastroenterol Hepatol. 2017; 40: 417-429.

3. Rajput R, Li W. Potential role of probiotics in mechanism of intestinal immunity. Pak Vet J. 2012; 32(3): 303-308.

4. Sánchez R, Omura M, Lucas A, Pérez T, Llanes M, De Luce S. Cepas de Lactobacillus spp. con capacidades probióticas aisladas del tracto intestinal de terneros neonatos. Rev Salud Anim. 2015; 37(2): 94-104.

5. García-Godos P. Evaluación de bacterias lácticas con capacidad antagónica frente a cepas patógenas aislada a partir de chicha de molle. Presentado en VII Congreso Nacional de Biología. 2006; Ayacucho, Perú.

6. Sacsaquisque R, Velásquez J. Manual de procedimientos para la prueba de sensibilidad antimicrobiana por el método se disco difusión. Lima: Instituto Nacional de Salud; 2002.

7. Villalobos R, Saldivar S, Moreno A. Implante histológico experimental de Trichinella spiralis en Rattus norvergicus "rata". Boletín Lima. 2008; 100(5):14-16.

8. Flores M. Capacidad prebiótica de Smallanthus sanchifolia "yacón" en Rattus norvergicus "rata". [Tesis para optar el título de Químico Farmacéutico]. Huamanga: Universidad Nacional de San Cristóbal de Huamanga; 2008. 
9. Delao N. Efecto de fructooligosacáridos de Cynara scolymus L. "alcachofa" en la producción de bacteriocinas por Lactobacillus spp. [Tesis para optar el título de Químico Farmacéutico]. Lima: UNMSM; 2016.

10. Brunce O. Inocuidad, prevención y riesgos de los probióticos. Rev Chil Pediatr. 2017; 88 (4): 534- 540.

11. Jurado H, Orbes A, Mesías L. Evaluación in vivo de Lactobacillus plantarum con características probióticas mediante química sanguínea, inmunohistoquímica y microscopía electrónica en Cavia porcellus. Rev Bio Agro. 2017; 15 (2):11-21.

12. Fujisawa N. The ability of probiotic bacteria to bind to human intestinal mucus. FEMS Microbiol Lett. 2008; 4(2): 5-7.

13. Fox S. Probiotics: Intestinal inoculants for production animal. Vet Med. 2007; 12(83): 806-818. 